\title{
THE THORACIC SURGERY FOUNDATION FOR RESEARCH AND EDUCATION
}

\section{Award Recipients}

he Thoracic Surgery Foundation for Research and Education is proud to support the following new research scholars for 2001:

Marc R. Moon, MD

2001-2003

Washington University School of Medicine

TSFRE Research Grant

Meena Nathan, MBBS, FRCS (Edin), FRCS (Glas)

2001-2003

Brigham and Women's Hospital

Nina S. Braunwald Research Fellowship Award

Alfred C. Nicolosi, MD

2001-2003

Medical College of Wisconsin

TSFRE Research Grant

This award is co-sponsored by the TSFRE and the CrossJones Research and Educational Fund of the St Luke's Foundation of Cleveland, Ohio.

\section{1-2002 Alley-Sheridan Sabbatical Scholar}

The Thoracic Surgery Foundation is pleased to announce that Drs William R. Berry of Napa, California, and Alan J. Spotnitz of New Brunswick, New Jersey, have been awarded Alley-Sheridan sabbatical scholarships to pursue an MPA at Harvard University's School of Public Health during the 20012002 academic year. 